\title{
MARKETING CAPABILITIES IN INTERNATIONAL MARKETING
}

\author{
Neil A. Morgan* \\ Indiana University \\ Kelley School of Business \\ 1309 E. Tenth St. \\ Bloomington, IN 47405-1701 \\ Phone: (812) 855-1114 \\ Email: namorgan@indiana.edu
}

\author{
Hui Feng \\ Iowa State University \\ Debbie and Jerry Ivy College of Business \\ 3337 Gerdin Business Building \\ Ames, IA 50011-1350 \\ Phone: (515) 294-3815 \\ Email: huifeng@iastate.edu \\ Kimberly A. Whitler \\ University of Virginia \\ Darden School of Business \\ 100 Darden Boulevard \\ Charlottesville, VA 22903
}

*Corresponding Author 


\title{
MARKETING CAPABILITIES IN INTERNATIONAL MARKETING
}

\begin{abstract}
There has been a significant increase in scholarly research focusing on marketing capabilities as an important aspect of marketing theory-based explanations of firm performance. This growing research interest in marketing capabilities has also been reflected in the international marketing literature. However, it is unclear whether and how thinking and research about international marketing capabilities differs from that of marketing capabilities in a domestic market context. To explore this question we conduct a review of studies of marketing capabilities in the most influential journals publishing research in international marketing. We supplement this with insights from interviews with a number of executives in different firms engaged to varying degrees in international marketing. Our study suggests that there remain numerous important unanswered questions in conceptualizing and empirically researching international marketing capabilities.

Keywords: Marketing Capabilities; International Marketing; Marketing Strategy; Marketing Performance
\end{abstract}

The concept of capabilities in the marketing literature is not new. Drawing on theory and empirical work in strategic management, capabilities are generally viewed as complex bundles of skills and knowledge embedded in the organizational processes by which a firm's available resources are transformed into valuable outputs (Day 1994). As capabilities are developed over time and become embedded in organizational processes and routines, they are difficult for rivals to observe and imitate, thereby enabling firms that possess them to enjoy sustainable competitive advantage (Grant 1996; Grewal and Slotegraaf 2007; Peteraf 1993). Marketing researchers have conceptualized marketing capabilities in terms of a firm's ability to use available resources to perform marketing tasks in ways that achieve desired marketing outcomes (Morgan, Katsikeas and Vorhies 2012). The literature suggests that marketing capabilities are especially valuable (Dutta, Narasimhan, and Rajiv 1999), inimitable (Morgan, Vorhies, and Mason 2009), and nonsubstitutable in creating sustainable competitive advantage and superior firm performance (Krasnikov and Jayachandran 2008; Moorman and Rust 1999). In international markets, 
marketing capabilities have also been shown to improve firm performance via enhancing the level and sustainability of realized positional advantages (e.g., see Tan and Sousa 2015 for a review).

Over the past 18 years, marketing scholars have intensified their focus on conceptualizing marketing capabilities and empirically examining their role in explaining firm performance. This growth in research attention has been mirrored in the international marketing literature. However, the extent to which conceptual and empirical approaches to studying marketing capabilities in the international context differ-and should differ-from those in domestic market contexts remains unclear. This is an important gap in existing knowledge in both theoretical and practical terms. From a theory perspective, it is difficult for researchers to accurately conceptualize and measure marketing capabilities without knowing whether and how they may be different in international (vs. purely domestic) market contexts. In addition, without an understanding of whether and how the mechanisms linking marketing capabilities with performance outcomes may (or may not) differ in international marketing contexts, it is difficult for researchers to know what types of mediators and moderators to study.

From a managerial perspective, managers want to know both what types of marketing capabilities may be appropriate for their firms and how to build, maintain and leverage themand the answers to these questions may vary based on the degree to which they operate in international markets and how they are organized to do so. Without understanding whether and how these international-related contingencies may matter, it is impossible for international marketing researchers to provide appropriate guidance to managers.

We address this important gap in knowledge in an effort to clarify thinking and provide guidance for future research in this theoretically interesting and managerially important area. As 
a starting point, we examine published research to identify and explore key differences between international and domestic marketing capabilities regarding their conceptualization, types, measurements, development, and relationships. We then further explore a number of important research questions arising from this analysis including: (i) drivers marketing capability development in international markets; (ii) whether and how can marketing capabilities help improve firm performance in the international markets; and, (iii) conditions that may enhance or weaken the marketing capability-firm performance relationship in international markets.

To accomplish this, we first review the literature to examine how marketing capabilities have been studied in international marketing contexts. Second, given important gaps identified in literature-based knowledge we supplement this literature-based analysis with insights from practice generated via in-depth interviews with executives in firms with varying degrees of internationalization. These inputs are then used to synthesize existing knowledge regarding marketing capabilities in international marketing, identify key knowledge gaps, and develop an agenda for future research in this important domain.

\section{REVIEW OF EXISTING RESEARCH}

Our literature review focuses on the most influential journals publishing international marketing research since 1999. To ensure the representativeness, completeness, and high quality of studies included in our review, the criteria for journal selection were based on previous ratings of journals in marketing and international business disciplines (Kirca and Yaprak 2010). In the marketing discipline, we chose six out of the ten most influential marketing journals from Baumgartner \& Pieters's (2003) study (i.e., Journal of Marketing (JM), Journal of Marketing Research (JMR), Marketing Science (MKS), Journal of the Academy of Marketing Science (JAMS), Journal of Retailing (JR), and Industrial Marketing Management (IMM)). The 
remaining four journals (i.e., Journal of Consumer Research, Harvard Business Review,

Management Science, and Advances in Consumer Research) on average have published only .8\% of international marketing related articles from 1975-2004 and are not typical publication outlets for marketing strategy studies (Leonidou et al. 2010). As all six journals are U.S.-based, we further added one international journal, International Journal of Research in Marketing (IJRM), because it is considered a top marketing journal in Europe (Kumar, Sharma, and Gupta 2017; Roberts, Kayande, and Stremersch 2014).

From the international business discipline, we added three of the six top journals from Dubois and Reed (2000)'s study (i.e., Journal of International Business Studies (JIBS), Journal of International Marketing (JIM), and International Marketing Review (IMR)). These are the most influential international business journals (Leonidou et al. 2010) focusing on marketing rather than management — the case with the remaining journals (i.e., Management International Review, Journal of World Business, and International Studies of Management and Organization).

These considerations led us to select 10 journals: JM, JMR, MKS, JAMS, JR, IMM, IJRM, JIBS, JIM and IMR. Eligible articles were identified by an issue-by-issue manual search for qualitative and empirical articles that have "marketing capability(ies)", "marketing competence(s)", "capabilities" and "competences" in their title, abstract, and keywords in each of these journals in EBSCO and journal publications websites.

Following procedures recommended for literature review papers (e.g., Lipsey and Wilson 2001, Katsikeas et al. 2016), when further examination was required, two experienced researchers separately examined the articles to determine inclusion. Five criteria had to be satisfied for a study to be eligible for this review: (i) the focus of the study must be on marketing 
capabilities $^{1}$, either as a primary objective or as part of a wider research design; (ii) the study examines firms engaged in international business i.e. the firm's operations and/or markets have to span multiple countries (e.g., multinational corporations-MNCs) or be export ventures, international new ventures/joint ventures (IJVs), or international logistics/outsourcing businesses, or the study examines firms from multiple countries; (iii) the unit of analysis is at the international micro-business level (e.g., export venture, international venture), i.e. the international context has to be a focus of the study rather than only a part of the sampling or a control variable; (iv) the study must be evidence-based (vs. purely conceptual) in nature, such as empirical papers using primary and/or secondary data, or qualitative research such as case studies and meta-analyses; and (v) the research must have been published since 1999, as very few studies of marketing capabilities were conducted before this period (Vorhies, Harker, and Rao 1999).

A total of 57 articles remained after this filtering process. Average interrater agreement was $93 \%$, and all remaining discrepancies were discussed to reach consensus. Finally, the search process was supplemented by scanning the reference lists of the articles collected to identify any additional relevant articles missed through the keyword searches. This produced an additional 7 articles from top management journals (e.g., Strategic Management Journal-SMJ, Journal of Management-JOM, and Decision Sciences-Dec. Sci.) for a total of 64 papers included in this review. For each of these 64 published studies, we then cataloged: (i) how they defined

\footnotetext{
${ }^{1}$ Marketing capabilities include but are not limited to pricing/new product development/promotion/ distribution/channel/brand management/market-based learning capabilities (see Morgan and Slotegraaf 2012 for a comprehensive list). We excluded idiosyncratic capabilities, such as "MNCs/exporters capability", "exploration/exploitation capability", "globalization/internationalization capability", "multicultural capabilities", "(dynamic) networking capability", "technology/IT capability", "MNC/global HRM capability", "(marketing) alliance (formation) capability" "dynamic/absorptive/learning capability", "knowledge management capability", "commercial capabilities", "local supplier/distributor capability", "international partners capability", and "global supply chain capability” (e.g., Usui, Kotabe, and Murray 2017).
} 
marketing capabilities and the theories on which the conceptualization draws; (ii) the types of marketing capabilities identified and/or examined; (iii) the marketing capability operationalization and analysis method used (for empirical studies); and, (iv) what the empirical studies report finding with respect to antecedents, consequences, moderators and mediators connected with marketing capabilities in international marketing. The answers to these four questions are summarized in the various tables and discussed in more detail below.

\section{- Insert Tables 1A, 1B \& 1C Here -}

\section{Marketing Capabilities: Definition and Theory}

In the general marketing literature, marketing capabilities are viewed in terms of a firm's ability to use available resources to perform marketing tasks in ways that achieve desired marketing outcomes (Day 1994; Morgan, Katsikeas and Vorhies 2012). They therefore represent the processes that a firm uses to define, develop, communicate and deliver value to its target customers by combining, transforming, and deploying its available resources (e.g., Bahadir, Bharadwaj, and Srivastava 2008; Morgan and Slotegraaf 2012). In the international marketing context, most studies define firm-level marketing capabilities in the same way as they are defined in the general marketing literature in domestic market contexts, and simply emphasize that the marketing activities and the processes by which they are accomplished are taking place in international markets in an effort to fulfill international customers' needs and achieve international marketplace goals (e.g., Lages, Silva, and Styles 2009; Shi et al. 2005; Zou, Fang, and Zhao 2003). Thus, firm-level marketing capabilities in international marketing are generally viewed in terms of a firm's ability to use available resources to understand and fulfill foreign market customer needs better than its rivals. Tables $1 \mathrm{~A}-1 \mathrm{C}$ provide a review of different marketing capabilities identified in the international marketing literature. 
A range of different theories are used to ground conceptualizations of marketing capabilities and hypothesize concerning their relationships with other phenomena in international marketing (see Web Appendix A). Unsurprisingly, as in the general marketing literature the majority of these draw on RBV theory. A large number also draw on dynamic capabilities (DC) theory, which given the difficulties associated with measuring dynamic phenomena can cause problems in matching theory to operationalization in many studies using primary survey research designs. A range of other theories used in domestic marketing contexts have also been applied in the internal marketing context, including organizational learning and the knowledge-based view. However, in a surprising number of studies (10 of the 64 studies in our sample), it is unclear what specific theory is being drawn upon to support the conceptualization of marketing capabilities in international markets.

The one theoretical viewpoint that is not used in the general marketing literature in domestic market contexts ${ }^{2}$ that has been used in a small number of international marketing studies in our sample is the Institution Based View. This perspective is based on institutional theory which focuses on institutional pressures such as industry or societal norms, regulations, and requirements that firms must adapt to in order to receive legitimacy, operate and serve customers in a country marketplace (e.g., Peng 2003). Such institutional forces may vary across different country marketplaces and can affect informal and formal marketing exchanges and thereby impact both the design and processes of an organization (e.g., Hult 2011).

Comparing specific marketing capabilities identified in the international marketing versus general marketing literature, we find only seven marketing capabilities that are specific/unique to studies in international marketplaces, and which could therefore potentially be considered

\footnotetext{
${ }^{2}$ The only exceptions here concern studies of firms that are based in an emerging market.
} 
“international marketing capabilities" (vs. simply general marketing capabilities in an international context). These are: MNCs' transnational product innovation capability (Sheng et al. 2015; Subramaniam and Venkatraman 2001); global brand management capability (Matanda and Ewing 2012); overseas market-related exploitative and explorative capabilities (Lisboa, Skarmeas, and Lages 2011); international customer-support capability (Khavul et al. 2010); adaptive capability (Lu et al. 2010), local market competence (Wu et al. 2007); and, global account management capability (Shi et al. 2005). Details of the research on these seven international marketing capabilities are summarized in Table 2.

\section{- Insert Table 2 Here -}

In the following section, we review the literature on marketing capabilities in international marketing in more detail from three perspectives: (i) the classification of marketing capabilities; (ii) the measurement and analysis of marketing capabilities; and (ii) the antecedents, mediators, moderators and consequences of marketing capabilities in international marketing.

\section{Marketing Capabilities: Classification}

As the notion of marketing capabilities is still relatively new to the marketing discipline (Morgan 2012), research in this area is still rather fragmented. However, the literature reveals several ways to classify different marketing capabilities. For example, adopting a market orientation perspective, Day (1994) classifies capabilities as outside-in, inside-out and spanning capabilities and identifies market sensing and customer-linking as the most important outside-in marketing capabilities. Day (2011) extends his earlier classification by proposing three subsets of marketing capabilities: (i) static marketing capabilities which include specialized/functional capabilities and cross-functional capabilities; (ii) dynamic marketing capabilities such as the ability to reconfigure and improve existing marketing capabilities; and (iii) adaptive marketing 
capabilities which deal with proactive vigilant marketing learning through experimentation and active interactions with network partners.

In a different approach drawing on interview and focus-group-based qualitative fieldwork with managers, Vorhies and Morgan $(2003,2005)$ classify marketing capabilities into two categories: specialized capabilities and architectural capabilities. Specialized capabilities refer to the lower-order, functionally-focused, marketing mix-related processes and routines such as pricing, advertising, product management, and channel management. Architectural capabilities such as marketing strategy planning and implementation capabilities deal with higher-order processes and routines that orchestrate and coordinate the firm's specialized marketing capabilities and their associated resource inputs. Morgan and Slotegraaf (2012) and Morgan (2012) build on this to provide a more extensive taxonomy by (i) adding a third type of marketing capability — cross-functional capabilities such as brand management and customer relationship management (CRM) that bring together multiple different functional inputs, and (ii) classifying marketing capabilities not only by their lower- to higher-order nature, but also by the different levels at which they exist: individual, group, organization, and inter-organizational levels, providing the most comprehensive framework available to-date for classifying various marketing capabilities.

Consistent with Morgan and Slotegraaf (2012)'s classification system, we classify the marketing capabilities in the representative set of studies we identified in the international marketing literature by their lower- to higher-order nature and the organizational levels at which they exist. Table 3 is adapted from Morgan and Slotegraaf (2012, p. 94) and summarizes the characteristics, examples, and representative studies of various types of marketing capabilities in the international market context. 


\section{- Insert Table 3 Here -}

Table 3 reveals that existing research on marketing capabilities in international markets has a heavy focus on mid-level marketing capabilities ( 35 of the 64 papers reviewed) compared with research in domestic markets which has generally focused to a greater degree on lower-level marketing capabilities. While a number of papers examining marketing capability in international markets also study lower-level marketing capabilities (23 of the 64 papers), very few focus on higher-level marketing capabilities ( 6 of the 64 papers). This is consistent withand may even be due to - the equally scant research on higher-level marketing capabilities in domestic market contexts in the general marketing literature.

Lower-level marketing capabilities are characterized by the specialized functional marketing processes used to design and implement individual marketing mix (4Ps) activities (e.g., Morgan, Katsikeas, and Vorhies 2012; Vorhies and Morgan 2005) such as pricing (e.g., Zou, Fang, and Zhao 2003), advertising and promotion (Chen 2008; De Carolis 2003), and selling (e.g., Lee and Zhou 2012). In the international market context, most research on lowerlevel marketing capabilities focuses on firm-level capabilities, particularly in the areas of advertising, marketing communications, and product management capabilities in foreign markets. In contrast, we observed no research on functional market research capabilities, and also none on individual- and group-level marketing capabilities such as overseas salesperson skills and overseas store management skills, perhaps due to the different nature of international selling (i.e., foreign sales) or difficulty in getting data regarding overseas retail stores.

Mid-level marketing capabilities are characterized by architectural or strategic marketing capabilities (Morgan et al. 2003; Morgan, Katsikeas, and Vorhies 2012) such as market-sensing (e.g., Kaufmann and Roesch 2012; Malik, Sinha, Blumenfeld 2012; Song et al. 2005), marketing 
strategy planning (e.g., Morgan, Katsikeas, and Vorhies 2012), and strategy implementation capabilities (e.g., Spyropoulou et al. 2017); cross-functional capabilities such as brand management (e.g., Erramilli, Agarwal, and Dev 2002), CRM (e.g., Reinartz, Krafft, and Hoyer 2004; Leonidou Palihawadana and Theodosiou 2011), and new product development (Kaleka 2011); and inter-organizational capabilities such as channel bonding and networking (Boso et al. 2013; Blesa and Ripolles 2008; Zhou, Wu, and Barnes 2012). We find that in the international context, environmental scanning or market-sensing capabilities are the most frequently studied mid-level capabilities. This makes sense given the increased complexity of the environment when dealing with international markets. Meanwhile, brand management capabilities are the least frequently studied mid-level marketing capability, which mirrors the equally scant research in a domestic market context (Morgan, Slotegraaf, and Vorhies 2009) and may be due — at least in part - to the relative lack of established scales for this capability. In comparison with domestic marketing capability research, studies in international marketing have paid relatively more attention to inter-organizational capabilities such as channel bonding and channel relationship management and networking capabilities, perhaps due to the importance of relying on local partners to understand and facilitate marketing operations in overseas markets in exporting - the most widely used mode of international market entry.

However, in general, marketing capability research in international markets is clearly dominated by firm-level marketing capabilities, with very few studies examining individual-level and group-level marketing capabilities. In addition, very few studies have focused on exploring higher-level, dynamic marketing capabilities associated with reconfiguring resources and enhancing current marketing capabilities. Examples of such higher-level marketing capabilities are market learning capabilities (e.g., Morgan 2012), adaptive capabilities (Lu et al. 2010), and 
inter-organizational learning capabilities (e.g., Selnes and Salis 2003). Marketing capability research in domestic markets has also studied some individual-level higher-order capabilities like adaptive selling (e.g., Spiro and Weitz 1990) and process thinking (e.g., Dickson et al. 2009). Research in our sample of studies in the international marketing context has not examined such marketing capabilities.

In general, such higher-order marketing capabilities are difficult to observe and measure, thus most studies of dynamic marketing capabilities adopt in-depth case study research designs (Evers, Andersson, and Hannibal 2012; Shi et al. 2005; Wilson and Daniel 2007). With few exceptions (e.g., Fang and Zou 2009), studies using primary survey data designs often conceptualize marketing capabilities as "dynamic" (or at least draw on dynamic capabilities theory) but measure them in a static way that does not reflect the "dynamism" proposed in the conceptualization (see detailed examples in Table 2) (e.g., Lages, Silva, and Styles 2009; Lisboa, Skarmeas, Lages 2011; Selnes and Sallis 2003). Nevertheless, theoretically dynamic marketing capabilities are widely considered to be the ultimate source of competitive advantage in complex and rapidly changing global markets as they allow firms to continuously update their lower-order marketing capabilities, and thus overcome path dependencies and avoid "competency traps" (Danneels 2002; March 1991; Morgan 2012). Given this, more research is clearly needed in the realm of higher-order dynamic marketing capabilities in both domestic and international markets.

\section{Marketing Capabilities: Measurement and Analysis Method}

Our review of the literature reveals that researchers have generally adopted one of three approaches to empirically investigate marketing capabilities: (i) direct observation using primary case studies; (ii) direct primary survey methods; and, (iii) inference-based approaches using secondary data. The first approach measures marketing capabilities through in-depth cases 
studies and we identified eight such studies in the international marketing research in our sample (see Table 1-A for a review). While such case studies provide in-depth understanding of firms' specific marketing capabilities in international markets, they suffer from small sample size and generalizability problems.

The second approach uses primary survey measures of marketing capabilities (see Table 1-B for a review), and this is the most frequently used method in studies in international marketing (64\%, or 41 of the 64 papers reviewed). Marketing managers responsible for the international market(s) in question generally serve as key informants and they are asked to rate how well their companies perform various marketing activities, often relative to their major competitors (e.g., Fang and Zou 2009; Spyropoulou et al. 2017). Given its widespread use in international marketing research, we further examined the types of operationalizations used in primary survey measures of marketing capabilities in our sample (see Web Appendix B). All of the 41 studies using survey approaches use multi-item scales, with the majority (63\%) employing 7-point scales and either "much worse/better" or "strongly agree/disagree" scale anchors. Almost half of the studies we reviewed (49\%) use absolute (vs. relative to rivals) measures of capabilities (i.e. how well various activities are performed) when asking managers to evaluate their marketing capabilities. ${ }^{3}$ The majority of the studies (71\%) draw on existing conceptualizations and/or measures, primarily from the general domestic marketing capabilities literature.

The primary survey approach is a direct method to assess marketing capabilities and it is flexible in enabling researchers to assess different types of marketing capabilities in various cultures and countries. However, there are two main problems with this method. First, with very

\footnotetext{
${ }^{3}$ This is often inconsistent with the implicit or explicit conceptualization and definition of marketing capabilities used in a study as being anchored on a relative-to-rivals basis.
} 
few exceptions (e.g., Boso et al. 2013), due to the difficulty of collecting data from the same firms at different points in time over long time-frames, survey studies use cross-sectional research designs, mostly with single-informants, and are therefore prone to common method bias. Second, data collected via primary surveys cannot empirically establish causal relationships that may be hypothesized with marketing capabilities. In addition, this research design approach often limits the number of different control variables that can be included in the data collection.

The third broad approach to assessing firms' marketing capabilities relies on proxy measures from secondary data to infer a firm's marketing capabilities (see Table1-C for a review) since no secondary data directly measuring firms marketing capabilities currently exists. There are generally two different methods used in this approach. One method uses marketing resource inputs such as advertising or SGA expenditures/sales (e.g., De Carolis 2003; Gao et al. 2010; Goerzen, Asmussen, and Nielsen 2013; Kotabe, Srinivasan, and Aulakh 2002) and selling expenses/sales (Anand and Delios 2002) or simply advertising expenses and time spent (Chen and Hennart 2002; Chen 2008; Wu 2013). The inference is that the more a firm allocates resources to something, the more likely they are to be or become good at it. This is the most widely adopted method to measure marketing capabilities using secondary data in international marketing. The second method uses marketing-related outcomes such as repeat client proportions (Ethiraj et al. 2005) to proxy how well a firm performs its marketing activities. This assumes that firms with better observed marketing-related outcomes have superior processes required to perform that activities that may deliver such outcomes. Both approaches have limitations in that the level of both (a) marketing resource deployments and (b) marketing-related outcomes represent only a part of the conceptualization of marketing capabilities as the firm's ability to use available resources to achieve desirable marketing outcomes. 
For this reason, scholars in the general domestic market context have begun to adopt "input-output" approaches using stochastic frontier estimation (SFE) as a third way to use secondary data to measure capabilities. This approach measures marketing capabilities by calibrating how well a firm transforms a given set of resources (e.g., advertising, sales expenses, trademarks) into certain desirable marketing-related outputs. Using SFE, this method estimates the maximum observed efficient frontier among firms in an industry in converting resources into desirable marketing output objectives in a sample of firms and then compares this maximum value with the actual resource-to-output performance of each firm in a sample. Greater deviations from the efficiency frontier value represent lower marketing capabilities.

This measurement approach offers several benefits. First, it is well aligned with the conceptualization of capabilities in that it calibrates how well a firm is able to deploy their available resources to implement marketing activities that achieve desired marketing outcomes relative to how well rivals do so. Thus, each firm is benchmarked in terms of its marketing capabilities against the best possible practices of firms with similar resources in the industry or sample of firms. Second, as it uses secondary data this method can enable researchers to examine the drivers and impact of marketing capabilities over longer time periods across firms — which is almost impossible to assess using primary data via case studies or surveys.

However, while this method has many merits and is gaining popularity in domestic market marketing capabilities research (e.g., Dutta, Narasimhan, and Rajiv 2005; Feng, Morgan, and Rego 2015, 2017; Xiong and Bharadwaj 2011), only two of the studies of marketing capabilities in international markets we reviewed have adopted this method (Akdeniz, GonzalezPadron, and Calantone 2010; Nath, Nachiappan, and Ramanathan 2010). This may be due to the difficulty of obtaining multiple input and international market output secondary data to calibrate 
marketing capabilities, or to the complexity/newness of this method.

We also examined the major methods of analysis used in exploring the relationships between marketing capabilities and other phenomena in the published international marketing research represented in our sample (see Web Appendix C). Most studies in our sample use structural equation modelling which reflects the relative popularity of studies using primary survey research designs. Regression-based approaches (both hierarchical and non-hierarchical) are also frequently used. The relative infrequency of econometric modeling approaches (including mixed models and fixed or random effects) also makes sense given the infrequent use of panel and time-series data in the studies in our sample.

- Insert Figure 1 Here -

\section{Marketing Capabilities: Antecedents, Moderators, Mediators and Consequences}

The role of marketing capabilities in explaining firm performance has been of increasing interest to marketing scholars as many have questioned the value of firms' marketing activities and investments (Rust et al. 2004). Generally, the literature suggests that firms with stronger marketing capabilities are better able to create value for customers and other stakeholders, and thereby achieve and sustain competitive advantage and superior financial performance (Day 1994; Morgan 2012). Though still relatively scant, a growing number of empirical studies have examined the impact of various marketing capabilities on different kinds of firm performance (mainly subjectively assessed) ranging from product-market performance indicators such as sales revenue, market share, sales growth, and customer satisfaction, to financial performance outcomes like cash flow, profitability, and ROI (Krasnikov and Jayachandran 2008). Research in international marketing also generally shows that marketing capabilities improve firms' financial and non-financial performance in international markets (Tan and Sousa 2015). 
Figure 1 synthesizes existing research on marketing capabilities in international marketing. Table 4 summarizes representative studies on the antecedents, mediators, and moderators of marketing capabilities in domestic versus international market contexts. This reveals that research on the antecedents of marketing capabilities in both domestic and international markets is scarce and has had a very limited focus. This lack of knowledge regarding the drivers of marketing capabilities is surprising given their theoretical importance in explaining marketing's role in firm performance. Most research on the antecedents of marketing capabilities has been limited to firm resources (e.g., Fang and Zou 2009), market knowledge (e.g., Morgan et al. 2003), and market orientation (e.g., Murray, Gao, and Kotabe 2011). Beyond these variables, explorations of the antecedents of marketing capabilities are fragmented. Domestic marketing capabilities research has explored strategy type as a driver (Vorhies, Morgan, and Autry 2009), while international marketing capabilities research has studied internationalization motivation/commitment (e.g., Kaufmann and Roesch 2012; Khavul et al. 2010), foreign participation/contact (e.g., Fahy et al. 2000; Wu et al. 2007), entrepreneurial orientation (Lisboa, Skarmeas, Lages 2011; O'Cass and Ngo 2011), and national exportpromotion programs (Leonidou, Palihawadana, and Theodosiou 2011) as drivers. While still small in number, a greater proportion of international than domestic studies have explored antecedents of marketing capabilities.

Regarding mediators of the marketing capabilities-firm performance relationship, there is relatively little research in domestic market contexts but a larger number of such studies in international markets. Competitive (positional) advantages, business strategy, implementation effectiveness and efficiency, innovation, and international-related factors such as international commitment, involvement, and entry modes have all been studied as mechanisms by which 
marketing capabilities impact firm performance. A meta-analysis by Tan and Sousa (2015) found that two types of competitive advantage (i.e. low-cost advantage and differentiation advantage) positively mediate the effect of marketing capabilities on financial and non-financial export performance. In general, understanding of the mediating mechanisms of how marketing capabilities impact firm performance is still in its infancy and remains under-researched in both domestic and international market contexts.

Table 4 also highlights the opportunity to investigate boundary conditions impacting the relationship between marketing capabilities and firm performance in international markets. Market environment (e.g., turbulence, competition) is the most frequently examined boundary condition in both domestic and international markets (e.g., Fang and Zou 2009; Kaleka and Morgan 2017). Explorations of other moderators of the marketing capabilities-firm performance relationship are rather fragmented. In the international market context, various institutional factors such as organization structure, inter-functional integration, ownership type, and countryspecific macro-environment factors such as socioeconomic and legal system, culture and social values, and economic development level have been extensively examined (e.g., Eisend, Evanschitzky, and Calantone 2016; Ozkaya et al. 2015; Wu 2013; Zhou, Wu and Barnes 2012). A number of other moderators such as firm efficiency, strategy, degree of export dependence, and firm reputation have also been explored in different contexts in international marketing (e.g., Erramilli, Agarwal, and Dev 2002; Murray, Gao, and Kotabe 2011; Nath, Nachiappan, and Ramanathan 2010; Prasad, Ramamurthy, and Naidu 2001). In domestic markets, various different moderators such as market entry timing, marketing plan characteristics, and marketing employee development capability have been explored (e.g., Ruiz-Ortega and García-Villaverde 2008; Slotegraaf and Dickson 2004; Orr, Bush, and Vorhies 2011). 
However, most of these moderators in international or domestic markets have only been examined once in a single study. Market turbulence is the only moderator that has been repeatedly tested in both domestic and international markets (Fang and Zou 2009; McKee, Varadarajan, and Pride 1989; Song et al. 2005). Unfortunately, researchers have reached conflicting conclusions regarding market turbulence's impact. For example, Fang and Zou (2009) find that market turbulence enhances the positive impact of marketing capabilities on firms' competitive advantage and financial performance in international joint ventures in China. In contrast, Song et al. (2005) find that the impact of marketing capabilities on joint venture performance is weaker in more technologically turbulent environments in joint ventures in U.S. Thus, no consensus has been reached regarding the fragmented moderators of the marketing capability-firm performance relationship proposed in various studies.

\section{- Insert Table 4 Here -}

\section{ADDITIONAL INSIGHTS FROM PRACTICE}

While there is a rich stream of literature in international business and international marketing investigating internationalization, and another in both the general and international marketing literature examining marketing capabilities, these two streams have not generally intersected. Given the lack of conceptual and empirical attention to the question of whether and how marketing capabilities may differ in international vs. domestic contexts apparent in our literature review, we sought additional insights on this question from practice. Specifically, we searched for insights addressing the key question "does marketing capability vary as a company migrates from a local to global focus, and if so, how and in what way?" Thus, from a practical standpoint we sought to begin to understand whether as firms move from a local to an international orientation, how and in what ways does this impact the firm's marketing capabilities (if at all)? 
Given the lack of existing empirical exploration on the topic, and the importance of generating insight from different perspectives, we interviewed five C-level executives (three CMOs and two Presidents who were former C-level marketers). The interviews were used to identify common conceptual themes that may serve to better understand differences between domestic and global marketing capabilities (Corbin and Strauss 2008). The interview protocol designed was reviewed by two academics and a practitioner (Kalton and Anderson 1986). Each reviewer was taken through the interview guide, asked to comment on clarity and length, and given an opportunity to suggest amendments or additional questions. This reviewer input led to revisions of the interview guides, which were then piloted with a C-level executive.

All of the interviews were confidential. The executives interviewed were from firms that varied in: size, industry, ownership (private/public), and customer type (B2B/B2C) (See Web Appendix D). Important for the research design, we ensured that we had balance across degree of internationalization, with two of the firms in expansionary stages of globalization and three firms in mature and broadly terminal stages of global development. This blend was important because as we anticipated, the challenges that firms on either end of the internationalization spectrum face may be different. All of the executives interviewed held or had held the top marketing position in their firms (i.e., their official titles could have been CMO or SVP Marketing).

To source respondents, we contacted executives within our own and our schools' network. As respondents were geographically dispersed, the interviews were conducted via telephone. The interview protocol consisted of open-ended questions and was structured in three parts: (i) background information related to the respondent (title, years with firm) and to the firm (industry, type of customer, firm size, degree of internationalization, etc.); (ii) the general differences in building and managing global (vs. domestic) marketing capabilities; and (iii) how 
specific characteristics (i.e., organization design/structure, process, talent, communication, and management) and capabilities may be associated with firms at varying levels of globalization (and associated with different stages of migration to a global marketing capability).

\section{Key Differences Between Domestic and Global Marketing Capability Development}

The fundamental question we asked is what changes with regard to a firm's marketing capabilities when the firm chooses to become more international. While a good deal of research attention has focused on examining firm internationalization, little of it has investigated this from a marketing capability perspective. Interestingly, one of the key insights from the interviews was that the answer to this question largely depended on the firm's degree of internationalization. In our research, three of the firms were fully global, having a majority of their revenue generated from outside of the U.S. and spread across multiple countries. The executives interviewed from these firms were not the architects that shaped the globalization of the firm but rather, had been placed in positions of authority in an already established global firm. The other two executives were members of the C-suite that were trying to increase the global footprint of their firms.

The responses from the two groups varied. Respondents in firms with established global operations found it more difficult to articulate how local versus global marketing capabilities were different. This is likely because they were stewards of already global firms rather than its original globalization architects. However, they suggested that the key ways in which local vs. global marketing capabilities differed centered on the complexity of the processes required to create, align, and manage marketing capabilities. As one commented:

"The process of marketing is identical no matter where you are practicing it. This was the most important 'aha'. The key is to ensure that everybody is actually using the same process and this is where globalization can lead to complexity. A CMO for one country comes from Unilever and another comes from Procter \& Gamble, and another comes from Pepsi. They all bring their own methods for generating consumer insight, their own processes for developing TV ads, their own methods for analyzing data, and even their own approaches to making a recommendation. This is when developing a global marketing capability can become a challenge. The key is to define 
one process, sell the entire organization on adhering to that one process, and ensure that everybody is trained globally on that process and held accountable for using that one process."

Respondents from the more mature, global firms consistently suggested that the difference between local and global marketing capability centered on aligning global leaders to all essentially "row in the same direction" in terms of using the same marketing processes to help increase speed, agility, and best practices redeployment. As one respondent suggested:

"The advantage of having global marketing capabilities is in scale, best practice development, and the muscle needed to build superior brands. The tension is that people want to do things their own way. Local is closer to the consumer, has better insight into local customs, habits, and practices, which leads to better granular understanding. However, if every country developed their own marketing capabilities, then you wouldn't have scale, or repeatable processes, or leverage...most countries would be less effective because they wouldn't be implementing proven best practices. While being global can slow things down (more agile iffighting locally), the benefit is that you learn from other cultures, you have more exposure to different ways of thinking about things, you learn more, and you can reapply to other parts of the world...best practices travel. So the priority has to be developing the processes that enable us to capture the learning, synthesize it, and export best practices to the globe. And this is not easy."

As this comment highlights, the more globally-mature company respondents tended to see mostly positives in developing global marketing capabilities, with the upside benefits of scale and best practice deployment being greater than the downside costs associated with potential lack of flexibility and less localization of marketing processes to deal with differences across countries. In contrast, respondents from less globally-mature companies focused primarily on the significant resource acquisition (both money and talent) and systems challenges associated with building international marketing capability. In explaining the challenge, one respondent relayed the following story:

"At one point, we were essentially a North American firm. While CMO, we decided to launch in two additional countries-one in Asia and one in Latin America. Now you have three climate regions which requires substantial product versioning. We then opened two other stores in another country. Each addition felt like something that was digestible, but, without knowing it, it added significant complexity. Running 18 promotions per country per year which had to be tailored to the locality...preparing for contingency sales and signage changes every 21 days... and then one country wants to have their own website. You have nuances in the language in social media. There are 500 holidays annually across our countries-and they don't line up globally. We are a fashion company and so things like sizing vary significantly by country.... going global was a three-year 
nightmare. To make this even more concrete, we didn't have the digital asset management systems or really good marketing automation systems or really good translation or even servers that would enable us to transfer huge images for trade show posters so that French Morocco can get the right poster and you don't end up starting a holy war. This isn't funny. We sent something meant for an Asian country to the middle-east and I was worried that our stores might get bombed. The big challenge is that building global marketing capabilities takes a lot more money and people than senior management want to throw at it. It takes time to generate the revenue and yet you need the resources up front. Everything I mentioned could be fixed with more people and more money... but you don't get that until you start shipping product globally and generating revenue. This is the problem."

In line with this resource constraints-related problem focus, another less globally-mature company respondent also focused on their firm's resource challenge:

"It simply takes a lot more resources-both money and people-to deal with the complexity of developing global marketing capabilities. Our goal is to become 50\% global, but it is a chicken and egg problem...I can't afford to run research studies in every country, I can't yet afford to establish regional marketing organizations (instead of managing it from the home office). And by not having local marketing folks, we may have to start developing a dealer/co-op program because we don't know the market well enough ... we may have to turn over the marketing to these markets. So without the talent, we can't effectively replicate the marketing that we conduct in the U.S., and therefore can't effectively market. I can't afford the talent until we get the sales...back to the chicken and egg problem."

Interestingly, overall the interviews suggest that firms seeking to become more global via establishing international operations (i.e. moving beyond simply exporting) are more focused on granular levels of lower-level marketing capability development in the countries in which they establish operations. In doing so, they face barriers primarily in obtaining required levels and types of resources to deploy in building such capabilities. In contrast, more globally mature firms are focused on architectural level capability refinement and improvement. In doing so, they face barriers in terms of gaining alignment to use common marketing processes when these may not necessarily be the most appropriate for the local market conditions.

\section{DISCUSSION AND IMPLICATIONS}

Our review of the representative research literature and qualitative fieldwork interviews reveal important gaps in conceptual and empirical knowledge regarding marketing capabilities in 
international marketing. In addition to the specific gaps already highlighted in our review of existing research, in the interests of guiding future research we focus here on the areas that we think hold the greatest promise for developing theoretically interesting and managerially relevant new knowledge in this increasingly important domain.

First, much greater conceptual attention is required to the fundamental question of whether and how international marketing capabilities are uniquely different. Our initial qualitative fieldwork data seem to suggest that the answer is "yes" with respect to there being differences in international vs. purely domestic marketing capabilities. However, it is unclear whether this is in terms of requiring different marketing capabilities or simply the ability to deal with the increased complexity created by cross-country differences in building and managing broadly the same marketing capabilities. Our fieldwork interviews indicate that at least the latter is the case. They suggest, for example, that building marketing capabilities across country markets requires greater resources, and may constrain (or enable) movement from one stage of internationalization to the next. Our interviews also indicate that identifying marketing best practices and processes across different country marketplaces and standardizing these across market-facing organizational units is required to enjoy benefits of scale.

On the bigger conceptual question of whether or not international marketing capabilities are fundamentally different in nature from those in purely domestic contexts, our initial fieldwork did not produce any obvious "yes" answer. The international marketing literature we examined is also generally undeveloped in this regard. The seven "different" marketing capability examples we uncovered in our review of representative studies may be viewed as being primarily different in terms of being contextually adapted versions of domestic marketing capabilities. For example, MNCs' transnational product innovation capability concerns a general 
product development capability that produces new products that fulfill needs across multiple country markets (Sheng et al. 2015; Subramaniam and Venkatraman 2001). Similarly, overseas market-related exploitative and explorative capabilities (Lisboa, Skarmeas, and Lages 2011) are applications of more general marketing-related capabilities to non-domestic markets. Likewise, both local market competence (Wu et al. 2007; Matanda and Ewing 2012) and adaptive capability (Lu et al. 2010), may be viewed as capturing the ability to apply more general market sensing and responsiveness capabilities to multiple different country marketplaces. Both global account management (Shi et al. 2005) and international customer-support (Khavul et al. 2010) capabilities are applications of general customer management capabilities customized to the particular needs of global customers. Finally, global brand management capability (Matanda and Ewing 2012) is the application of brand management in a global setting.

All of this would seem to suggest that the primary difference between in international vs. domestic marketing capabilities concerns the ability to create, maintain, and leverage the same set of general marketing capabilities in ways that cope with context-based variance across country markets and organizational differences across units catering to different markets. Yet, it remains unclear whether such international vs. domestic market context differences are different in either nature or scale between, for example, a firm operating across multiple different productmarkets in a single country vs. a firm operating in a single product-market segment across different country marketplaces. Beyond the need to be adapted to contextual international differences, are there any novel capabilities that are required solely for marketing in international markets? Conceptual and empirical research on this fundamental question is sorely needed.

Second, while it is true that the antecedents of marketing capabilities and mechanisms by which marketing capabilities may contribute to performance outcomes have generally been a 
greater focus of researchers in international vs. domestic marketing contexts, much remains to be explored. In particular, some of the antecedents explored in a domestic market context have received very little attention in an international market context. For example, how does the presence of a $\mathrm{CMO}$ or marketing department power within the firm affect international marketing capabilities? Similarly, some of the capability-performance mechanisms explored in a domestic market context have received little research attention in international marketing. For example, studies in a domestic market context have shown that an important route by which marketing capabilities contribute to firm performance is by "adding value" to a firm's assets such as market knowledge (e.g., Morgan, Vorhies, and Mason 2009) or brands (e.g., Wiles, Morgan, and Rego 2012). Does this also occur in leveraging firms' assets across country marketplaces? If so, are marketing capabilities more complementary to some types of assets than others? Do these assets differ between within and across country contexts?

In addition, from a performance-enhancing mechanism perspective our qualitative fieldwork suggests the possibility that there may be marketing capability economies of scale and scope available to a firm operating across country marketplaces. In particular, our interviews suggested that global firms may be exposed to a greater variety of different marketing practices, and that from among these they can select "best practices" and standardize these across their myriad different organizational units across country markets. Essentially, countries operate as test markets through which best practices are identified and then exported to other markets within the firm. These are potential performance-enhancing mechanisms of marketing capabilities in international marketing that have received almost no research attention to-date. If these marketing capability performance-enhancing mechanisms do exist in global firms how may they be different in nature and scale to those available to domestic firms operating across 
multiple different product-markets in a single country? For example, are domestic firms exposed to less variety in marketing practices but find it easier to transfer best practices among organizational units - or vice versa? In addition, what are the downside costs associated with such cross-country standardization? When may these outweigh the benefits?

Third, our fieldwork and observations across some of the studies we reviewed strongly suggest that a key difference of marketing capabilities in international marketing is the ability to operate effectively and efficiently within and across the organizational units by which firms interact with different country marketplaces. Importantly, this suggests that marketing capabilities will likely differ across firms in different stages of internationalization. In our review of the international marketing literature we found numerous studies of marketing capabilities within stages of internationalization. For example, there are a large (and growing) number of studies examining marketing capabilities in exporting manufacturers, and a smaller (but also growing) number of studies in MNC and IJV contexts. However, there have been few (any?) studies that examine the extent to which marketing capabilities (and their antecedents, consequences, moderators, and mediators) differ across firms at different stages of internationalization. There may be much to be learned from such studies, including answers to questions such as whether or not "fit" between marketing capabilities and stage of internationalization impact firm performance. Furthermore, what is the role of marketing capability development in enhancing or inhibiting firms' movement from one stage of internationalization to another?

This naturally also leads to additional questions in the realm of the nature of dynamic marketing capabilities. Dynamic capabilities theory is oft-cited but has been infrequently empirically studied in international marketing research. Firms operating in international markets 
may be exposed to a greater variety marketplace environments, all of which may be changing in different ways and at different rates. The need to effectively and efficiently deal with such dynamic complexity would suggest that dynamic marketing capabilities may be particularly valuable for firms operating in international markets. Yet, difficulties in measuring such marketing capabilities in a dynamic manner (i.e. observing marketplace change (or anticipated change)-driven shifts in firms' resource and capability configurations over time) using primary case study and survey research designs have severely limited our knowledge to-date. This is perhaps why we currently know much more about firms' ability to sense their marketplace environments, than we do about how they are able to acquire, improve and reconfigure marketing-related resources and capabilities designed to match the changing marketplace environments faced by the firm.

However, it is possible to design even survey-based measures that better capture the dynamic (vs. static) aspects and changing nature of marketing capabilities, and researchers should be encouraged to do so in order to explore how firms evaluate, develop, integrate, monitor and manage such dynamic marketing capabilities. Alternatively, researchers can explore using secondary data approaches in panel data where firm-specific changes over time may be used to infer such dynamic marketing capabilities, and this may offer another route forwards for future research.

Perhaps even more important from a practice perspective is the question of how marketing capabilities — dynamic and operational — can best be built, maintained, improved, and leveraged in firms operating in international markets. Drawing on the sizable and growing research literature, there appears to be little doubt that marketing capabilities are generally valuable in enabling firms operating in international markets to enjoy superior performance. 
Research to-date is helpful for managers in understanding what types of marketing capabilities may be particularly valuable under certain conditions. However, once they understand and believe the performance-enhancing value of marketing capabilities, managers inevitably want to know "how do I build such capabilities in my firm?" While international marketing researchers have studied a number of antecedents of marketing capabilities, almost all of these have been from the perspective of different types of knowledge and other resource inputs that are deployed by various marketing capabilities. We have little or no knowledge of how marketing capabilities can be deliberately and pro-actively built and improved to match the international marketplace environments faced. Yet, theoretically the ability to do so is a core component of dynamic marketing capabilities. It is also the primary question that managers would like answered. How should I go about building marketing capabilities across country markets? Which skills are portable and which are not? Who should own marketing capability development and compliance? All of these key managerial questions are currently unanswered in existing research.

\section{CONCLUSIONS}

Marketing capabilities has been a growing area of interest among international marketing researchers. Despite the progress in unpacking the performance implications, drivers, moderators, and mediators of marketing capabilities, our review of the literature and qualitative fieldwork interviews reveal important gaps in conceptual and empirical knowledge regarding marketing capabilities in international marketing. Clearly, there remains important work to be done in this theoretically important and managerially interesting domain. This study provides a number of new directions that may be helpful in guiding research attention to those questions that may offer the greatest contributions to both theory and practice in international marketing. 


\section{REFERENCES}

*Akdeniz, M. Billur, Tracy Gonzalez-Padron, and Roger J. Calantone (2010), "An Integrated Marketing Capability Benchmarking Approach to Dealer Performance through Parametric and Nonparametric Analyses." Industrial Marketing Management, 39(1), 150-160.

*Anand, Jaideep and Andrew Delios (2002), "Absolute and Relative Resources as Determinants of International Acquisitions," Strategic Management Journal, 23(2), 119-134.

Bahadir, S. Cem, Sundar G. Bharadwaj, and Rajendra K. Srivastava (2008), "Financial Value of Brands in Mergers and Acquisitions: Is Value in the Eye of the Beholder?" Journal of Marketing, 72(6), 49-64.

Baumgartner, H., \& Pieters, R. (2003), "The Structural Influence of Marketing Journals: A Citation Analysis of the Discipline and its Sub-Areas over Time," Journal of Marketing, 67(2), 123-139.

*Blesa, Andreu, and Maria Ripolles (2008), "The Influence of Marketing Capabilities on Economic International Performance," International Marketing Review, 25(6), 651-673.

*Bortoluzzi, Guido, Maria Chiarvesio, Eleonora Di Maria, and Raffaella Tabacco (2014), "Exporters Moving Toward Emerging Markets: A Resource-Based Approach," International Marketing Review, 31(5), 506-525.

*Boso, Nathaniel, Vicky M. Story, John W. Cadogan, Milena Micevski, and Selma KadićMaglajlić (2013), "Firm Innovativeness and Export Performance: Environmental, Networking, and Structural Contingencies," Journal of International Marketing, 21(4), 62-87.

*Chen, Shih-Fen (2008), "The Motives for International Acquisitions: Capability Procurements, Strategic Considerations, and the Role of Ownership Structures," Journal of International Business Studies, 39(3), 454-471.

*__ and Jean-Francois Hennart (2002), "Japanese Investors' Choice of Joint Ventures versus Wholly-Owned Subsidiaries in the US: The Role of Market Barriers and Firm Capabilities," Journal of International Business Studies, 33(1), 1-18.

*Chen, Xiaoyun, Alex Xin Chen, and Kevin Zheng Zhou (2014) "Strategic Orientation, Foreign Parent Control, and Differentiation Capability Building of International Joint Ventures in An Emerging Market," Journal of International Marketing, 22(3), 30-49.

Corbin, Juliet, and Anselm Strauss (2008), Basics of Qualitative Research. London: Sage Publications.

Day, George S. (1994), "The Capabilities of Market-Driven Organizations," Journal of Marketing, 58(4), 37-52.

_ (2011), "Closing the Marketing Capabilities Gap," Journal of Marketing, 75(4), 183-95.

Danneels, Erwin (2002), "The Dynamics of Product Innovation and Firm Competences," Strategic Management Journal, 23(12), 1095-121.

*De Carolis, Donna Marie (2003), "Competencies and Imitability in the Pharmaceutical Industry: An Analysis of Their Relationship with Firm Performance," Journal of Management, 29(1), 27-50. 
*DeSarbo, Wayne S., C. Anthony Di Benedetto, and Indrajit Sinha (2005), "Revisiting the Miles and Snow Strategic Framework: Uncovering Interrelationships between Strategic Types, Capabilities, Environmental Uncertainty, and Firm Performance," Strategic Management Journal, 26(1), 47-74.

Dubois, F., \& Reeb, D. M. (2000), “Ranking the International Business Journals,” Journal of International Business Studies, 31(4), 689-704.

Dutta, Shantanu, Om Narasimhan, and Surendra Rajiv (1999), "Success in High-Technology Markets: Is Marketing Capability Critical?," Marketing Science, 18 (4), 547-68.

- $\longrightarrow$, and (2005), "Conceptualizing and Measuring Capabilities:

Methodology and Empirical Application," Strategic Management Journal, 26(3), 277-85.

Dickson, Peter R., Walfried M. Lassar, Gary Hunter, and Samit Chakravorti (2009), "The Pursuit of Excellence in Process Thinking and Customer Relationship Management," Journal of Personal Selling and Sales Management, 29(2), 111-24.

*Eisend, Martin, Heiner Evanschitzky, and Roger J. Calantone (2016), "The Relative Advantage of Marketing over Technological Capabilities in Influencing New Product Performance: The Moderating Role of Country Institutions," Journal of International Marketing, 24(1), 41-56.

*Erramilli, M. Krishna, Sanjeev Agarwal, and Chekitan S. Dev (2002), "Choice between NonEquity Entry Modes: An Organizational Capability Perspective," Journal of International Business Studies, 33(2), 223-242.

*Ethiraj, Sendil K., Prashant Kale, M. S. Krishnan, and Jitendra V. Singh (2005), "Where Do Capabilities Come from and How Do They Matter? A Study in the Software Services Industry," Strategic Management Journal, 26(1), 25-45.

*Evers, Natasha, Svante Andersson, and Martin Hannibal (2012), "Stakeholders and Marketing Capabilities in International New Ventures: Evidence from Ireland, Sweden and Denmark," Journal of International Marketing, 20(4), 46-71.

*Fahy, John, Graham Hooley, Tony Cox, Jozsef Beracs, Krzysztof Fonfara, and Boris Snoj (2000), "The Development and Impact of Marketing Capabilities in Central Europe," Journal of International Business Studies, 31(1), 63-81.

*Fang, Eric Er and Shaoming Zou (2009), "Antecedents and Consequences of Marketing Dynamic Capabilities in International Joint Ventures," Journal of International Business Studies, 40(5), 742-761.

Feng, Hui, Neil A. Morgan, and Lopo L. Rego (2015), "Marketing Department Power and Firm Performance," Journal of Marketing, 79(5), 1-20.

— _ - (2017), "Firm Capabilities and Growth: The Moderating Role of Market Conditions," Journal of the Academy of Marketing Science, 45(1), 76-92.

*Freeman, Joanne and Chris Styles (2014), "Does Location Matter to Export Performance?" International Marketing Review, 31(2), 181-208.

*Gao, Gerald Yong, Janet Y. Murray, Masaaki Kotabe, and Jiangyong Lu (2010), "A "Strategy Tripod" Perspective on Export Behaviors: Evidence from Domestic and Foreign Firms Based in an Emerging Economy," Journal of International Business Studies, 41(3), 377-396. 
*Gregory, Gary D., Liem Viet Ngo, and Munib Karavdic (2017), "Developing E-Commerce Marketing Capabilities and Efficiencies for Enhanced Performance In Business-to-Business Export Ventures," Industrial Marketing Management, in press.

*Goerzen, Anthony, Christian Geisler Asmussen, and Bo Bernhard Nielsen (2013), "Global Cities and Multinational Enterprise Location Strategy," Journal of International Business Studies, 44(5), 427-50.

Grant, Robert M. (1996), "Prospering in Dynamically-Competitive Environments: Organizational Capability as Knowledge Integration," Organization Science, 7(4), 375-87.

Grewal, Rajdeep, and Rebecca J. Slotegraaf (2007), "Embeddedness of Organizational Capabilities," Decision Sciences, 38(3), 451-88.

Hult, G. Tomas M. (2011), "Toward a Theory of the Boundary-Spanning Marketing Organization and Insights from 31 Organization Theories," Journal of the Academy of Marketing Science, 39 (4), 509-36.

*Kaleka, Anna (2002), "Resources and Capabilities Driving Competitive Advantage in Export Markets: Guidelines for Industrial Exporters," Industrial Marketing Management, 31(3), 273-83.

*__ (2011), "When Exporting Manufacturers Compete on the Basis of Service: Resources and Marketing Capabilities Driving Service Advantage and Performance," Journal of International Marketing, 19(1), 40-58.

*__ and Neil A. Morgan (2017), "How Marketing Capabilities and Current Performance Drive Strategic Intentions in International Markets," Industrial Marketing Management, 1-14. Kalton, Graham, and Dallas W. Anderson (1986), "Sampling Rare Populations," Journal of the Royal Statistical Society, 149(1), 65-82.

Katsikeas, Constantine S., Neil A. Morgan, Leonidas C. Leonidou, and G. Tomas M. Hult (2016), "Assessing Performance Outcomes in Marketing," Journal of Marketing, 80(2), 1-20.

*Kaufmann, Lutz and Jan-Frederik Roesch (2012), "Constraints to Building and Deploying Marketing Capabilities by Emerging Market Firms in Advanced Markets," Journal of International Marketing, 20(4), 1-24.

*Kemper, Jan, Andreas Engelen, and Malte Brettel (2011), "How Top Management's Social Capital Fosters the Development of Specialized Marketing Capabilities: A Cross-Cultural Comparison," Journal of International Marketing, 19(3), 87-112.

*Khavul, Susanna, Mark Peterson, Drake Mullens, and Abdul A. Rasheed (2010), "Going Global with Innovations from Emerging Economies: Investment in Customer Support Capabilities Pays Off," Journal of International Marketing, 18(4), 22-42.

Kirca, A.H. and Yaprak, A. (2010), "The Use of Meta-Analysis in International Business Research: Its Current Status and Suggestions for Better Practice," International Business Review, 19 (3), 306-314.

*Knight, Gary, Tage Koed Madsen, and Per Servais (2004), "An Inquiry into Born-Global Firms in Europe and the USA," International Marketing Review, 21(6), 645-665.

*Kotabe, Masaaki, Srini S. Srinivasan, and Preet S. Aulakh (2002), "Multinationality and Firm Performance: The Moderating Role of R\&D and Marketing Capabilities," Journal of 
International Business Studies, 33(1), 79-97.

*Konwar, Ziko, Nikolaos Papageorgiadis, Mohammad Faisal Ahammad, Yumiao Tian, Frank McDonald, Chengang Wang (2017), "Dynamic Marketing Capabilities, Foreign Ownership Modes, Sub-National Locations and the Performance of Foreign Affiliates in Developing Economies." International Marketing Review, 34 (5), 674-704.

*Krasnikov, Alexander and Satish Jayachandran (2008), "The Relative Impact of Marketing, Research-and-Development, and Operations Capabilities on Firm Performance," Journal of Marketing, 72(4), 1-11.

Kumar, V., Amalesh Sharma, and Shaphali Gupta (2017), "Accessing the Influence of Strategic Marketing Research on Generating Impact: Moderating Roles of Models, Journals, and Estimation Approaches," Journal of the Academy of Marketing Science, 45 (2), 164-185.

*Lages, Luis Filipe, Graça Silva, and Chris Styles (2009), "Relationship Capabilities, Quality, and Innovation as Determinants of Export Performance," Journal of International Marketing, 17(4), 47-70.

*Lee, Ruby P. and Kevin Zheng Zhou (2012), "Is Product Imitation Good for Firm Performance? An Examination of Product Imitation Types and Contingency Factors," Journal of International Marketing, 20(3), 1-16.

Leonidou, Leonidas C., Bradley R. Barnes, Stavroula Spyropoulou, and Constantine S. Katsikeas (2010), "Assessing the Contribution of Leading Mainstream Marketing Journals to the International Marketing Discipline," International Marketing Review, 27(5), 491-518.

*___ Dayananda Palihawadana, and Marios Theodosiou, (2011), "National Export-

Promotion Programs as Drivers of Organizational Resources and Capabilities: Effects on Strategy, Competitive Advantage, and Performance," Journal of International Marketing, 19(2), $1-29$.

Lipsey, Mark W. and David B. Wilson (2001), Practical Meta-Analysis. Thousand Oaks, CA: Sage Publications.

*Lisboa, Ana, Dionysis Skarmeas, and Carmen Lages (2011), "Entrepreneurial Orientation, Exploitative and Explorative Capabilities, and Performance Outcomes in Export Markets: A Resource-Based Approach," Industrial Marketing Management, 40(8), 1274-84.

*Lu, Yuan, Lianxi Zhou, Garry Bruton, and Weiwen Li (2010), "Capabilities as a Mediator Linking Resources and the International Performance of Entrepreneurial Firms in an Emerging Economy," Journal of International Business Studies, 41(3), 419-436.

*Malik, Ashish, Ashish Sinha, and Stephen Blumenfeld (2012), "Role of Quality Management Capabilities in Developing Market-Based Organisational Learning Capabilities: Case Study Evidence from Four Indian Business Process Outsourcing Firms," Industrial Marketing Management, 41(4),639-48.

March, James G. (1991), "Exploration and Exploitation in Organizational Learning," Organization Science, 2(1), 71-87.

*Mariadoss, Babu John, Patriya Silpakit Tansuhaj, and Nacef Mouri (2011), "Marketing Capabilities and Innovation-Based Strategies for Environmental Sustainability: An Exploratory Investigation of B2B Firms," Industrial Marketing Management, 40(8), 1305-18. 
*Matanda, Tandadzo, and Michael T. Ewing (2012) "The Process of Global Brand Strategy Development and Regional Implementation," International Journal of Research in Marketing, 29(1), 5-12.

Mckee, Daryl O., P. Rajan Varadarajan, and William M. Pride (1989), "Strategic Adaptability and Firm Performance: A Market-Contingent Perspective," Journal of Marketing, 53(3), 21-35.

Moorman, Christine and Roland T. Rust (1999), "The Role of Marketing," Journal of Marketing, 63(SI), 180-97.

Morgan, Neil A. (2012), "Marketing and Business Performance," Journal of the Academy of Marketing Science, 40(1), 102-119.

— , and Rebecca J. Slotegraaf (2012), "Marketing Capabilities for B2B Firms," in Gary Lilien and Raj Grewal (eds.) Business to Business Marketing Handbook, Elgar: Northampton, MA, 90-108.

*___ Constantine S. Katsikeas, and Douglas W. Vorhies (2012), "Export Marketing Strategy Implementation, Export Marketing Capabilities, and Export Venture Performance," Journal of the Academy of Marketing Science, 40(2), 271-289.

*___ Anna Kaleka, and Constantine S. Katsikeas (2004), "Antecedents of Export Venture Performance: A Theoretical Model and Empirical Assessment," Journal of Marketing, 68(1), 90108.

, Douglas W. Vorhies, and Charlotte H. Mason (2009), "Market Orientation, Marketing Capabilities, and Firm Performance," Strategic Management Journal, 30(8), 909-20.

— Rebecca J. Slotegraaf, and Douglas W. Vorhies (2009), "Linking Marketing Capabilities with Profit Growth," International Journal of Research in Marketing, 26(4), 284-93.

*___ Shaoming Zou, Douglas W. Vorhies, and Constantine S. Katsikeas (2003), "Experiential and Informational Knowledge, Architectural Marketing Capabilities, and the Adaptive Performance of Export Ventures," Decision Sciences, 34(2), 287-321.

*Mu, Jifeng (2015), "Marketing Capability, Organizational Adaptation and New Product Development Performance," Industrial Marketing Management, 49(1), 151-166.

*Murray, Janet Y., Gerald Yong Gao, and Masaaki Kotabe (2011), "Market Orientation and Performance of Export Ventures: The Process through Marketing Capabilities and Competitive Advantages," Journal of the Academy of Marketing Science, 39(2), 252-269.

*Nath, Prithwiraj, Subramanian Nachiappan, and Ramakrishnan Ramanathan (2010), "The Impact of Marketing Capability, Operations Capability and Diversification Strategy on Performance: A Resource-Based View," Industrial Marketing Management, 39(2), 317-29.

*O'Cass, Aron, and Liem Viet Ngo (2011), "Winning Through Innovation and Marketing: Lessons from Australia and Vietnam," Industrial Marketing Management, 40(8), 1319-29.

Orr, Linda M., Victoria D. Bush, and Douglas W. Vorhies (2011), "Leveraging Firm-Level Marketing Capabilities with Marketing Employee Development," Journal of Business Research, 64(10), 1074-81.

*Ozkaya, H. Erkan, Cornelia Droge, G. Tomas M. Hult, Roger Calantone, and Elif Ozkaya (2015), "Market Orientation, Knowledge Competence, and Innovation," International Journal of Research in Marketing, 32(3), 309-318. 
Peng, Mike W (2003), "Institutional Transitions and Strategic Choices," Academy of Management Review, 28 (2), 275-96.

Peteraf, Margaret A (1993), "The Cornerstones of Competitive Advantage: A Resource - Based View," Strategic Management Journal, 14(3), 179-91.

*Perks, Helen (2005), "Specifying and Synchronising Partner Activities in the Dispersed Product Development Process," Industrial Marketing Management, 34(1), 85-95.

*Pham, Thi Song Hanh, Lien Le Monkhouse, and Bradley R. Barnes (2017), "The Influence of Relational Capability and Marketing Capabilities on the Export Performance of Emerging Market Firms." International Marketing Review, 34(5), 606-28.

*Prasad, V. Kanti, Keshavamurthy Ramamurthy, and G. M. Naidu (2001), "The Influence of Internet-Marketing Integration on Marketing Competencies and Export Performance," Journal of International Marketing, 9(4), 82-110.

*Reinartz, Werner, Manfred Krafft, and Wayne D. Hoyer (2004), "The Customer Relationship Management Process: Its Measurement and Impact on Performance," Journal of Marketing Research, 41(3), 293-305.

Roberts, John H., Ujwal Kayande, and Stefan Stremersch (2014), "From Academic Research to Marketing Practice: Exploring the Marketing Science Value Chain," International Journal of Research in Marketing, 31(2), 127-140.

Ruiz-Ortega, María José, and Pedro Manuel García-Villaverde (2008), "Capabilities and Competitive Tactics Influences on Performance: Implications of The Moment of Entry," Journal of Business Research, 61(4), 332-345.

Rust, Roland T., Tim Ambler, Gregory S. Carpenter, V. Kumar, and Rajendra K. Srivastava (2004), "Measuring Marketing Productivity: Current Knowledge and Future Directions," Journal of Marketing, 68(4), 76-89.

*Selnes, Fred and James Sallis (2003), "Promoting Relationship Learning," Journal of Marketing, 67(3), 80-95.

*Sheng, Margaret L., Nathaniel N. Hartmann, Qimei Chen, and Irene Chen (2015), "The Synergetic Effect of Multinational Corporation Management's Social Cognitive Capability on Tacit-Knowledge Management: Product Innovation Ability Insights from Asia," Journal of International Marketing, 23(2), 94-110.

*Shi, Linda H., J. Chris White, Regina C. McNally, S. Tamer Cavusgil, and Shaoming Zou (2005), "Executive Insights: Global Account Management Capability: Insights from Leading Suppliers," Journal of International Marketing, 13(2), 93-113.

Slotegraaf, Rebecca J. and Peter. R. Dickson (2004), "The Paradox of a Marketing Planning Capability," Journal of the Academy of Marketing Science, 32(4), 371-85.

*Song, Michael, Cornelia Droge, Sangphet Hanvanich, and Roger Calantone (2005), "Marketing and Technology Resource Complementarity: An Analysis of their Interaction Effect in Two Environmental Contexts," Strategic Management Journal, 26(3), 259-276. 
*___ Robert W. Nason, and C. Anthony Di Benedetto (2008), "Distinctive Marketing and Information Technology Capabilities and Strategic Types: A Cross-National Investigation," Journal of International Marketing, 16(1), 4-38.

*Spyropoulou, Stavroula, Constantine S. Katsikeas, Dionysis Skarmeas, and Neil A. Morgan (2017), "Strategic Goal Accomplishment in Export Ventures: The Role of Capabilities, Knowledge, and Environment," Journal of the Academy of Marketing Science, 1-21.

Spiro, Rosann L. and Barton A. Weitz (1990), "Adaptive Selling: Conceptualization, Measurement, and Nomological Validity," Journal of Marketing Research, 27(1), 61-69.

*Subramaniam, Mohan and N. Venkatraman (2001), "Determinants of Transnational New Product Development Capability: Testing the Influence of Transferring and Deploying Tacit Overseas Knowledge," Strategic Management Journal, 22(4), 359-378.

*Tan, Qun and Carlos MP Sousa (2015), "Leveraging Marketing Capabilities into Competitive Advantage and Export Performance," International Marketing Review, 32(1), 78-102.

Trainor, Kevin J., Adam Rapp, Lauren Skinner Beitelspacher, and Niels Schillewaert (2011), "Integrating Information Technology and Marketing: An Examination of the Drivers and Outcomes of E-Marketing Capability," Industrial Marketing Management, 40(1), 162-74.

Usui, Tetsuya, Masaaki Kotabe, and Janet Y. Murray (2017), "A Dynamic Process of Building Global Supply Chain Competence by New Ventures: The Case of Uniqlo," Journal of International Marketing, 25(3), 1-20.

*Vicente, Margarida, José Luís Abrantes, and Mário Sérgio Teixeira (2015), "Measuring Innovation Capability in Exporting Firms: The INNOVSCALE," International Marketing Review, 32(1), 29-51.

Vorhies, Douglas W., Michael Harker, and C. P. Rao (1999), "The Capabilities and Performance Advantages of Market-Driven Firms," European Journal of Marketing, 33(11/12), 1171-1202.

and Neil. A. Morgan (2003), "A Configuration Theory Assessment of Marketing Organization Fit with Business Strategy and Its Relationship with Marketing Performance," Journal of Marketing, 67(1), 100-15.

— and (2005), "Benchmarking Marketing Capabilities for Sustainable Competitive Advantage," Journal of Marketing, 69(1), 80-94.

— Linda M. Orr, and Victoria D. Bush (2011), "Improving Customer-Focused Marketing Capabilities and Firm Financial Performance Via Marketing Exploration and Exploitation," Journal of the Academy of Marketing Science, 39(5), 736-56.

, Robert E. Morgan, and Chad W. Autry (2009), "Product-Market Strategy and the Marketing Capabilities of the Firm: Impact on Market Effectiveness and Cash Flow Performance," Strategic Management Journal, 30(12), 1310-34.

*Wilson, Hugh and Elizabeth Daniel (2007), "The Multi-Channel Challenge: A Dynamic Capability Approach," Industrial Marketing Management, 36(1), 10-20.

Wiles, Michael A, Neil A Morgan, and Lopo L Rego (2012), "The Effect of Brand Acquisition and Disposal on Stock Returns," Journal of Marketing, 76 (1), 38-58. 
*Wu, Fang, Rudolf R. Sinkovics, S. Tamer Cavusgil, and Anthony S. Roath (2007), "Overcoming Export Manufacturers' Dilemma in International Expansion," Journal of International Business Studies, 38(2), 283-302.

*Wu, Jie (2013), "Marketing Capabilities, Institutional Development, and the Performance of Emerging Market Firms: A Multinational Study," International Journal of Research in Marketing, 30(1), 36-45.

Xiong, Guiyang and Sundar Bharadwaj (2011), "Social Capital of Young Technology Firms and Their IPO Values: The Complementary Role of Relevant Absorptive Capacity," Journal of Marketing, 75(6), 87-104.

*Zhou, Lianxi, Aiqi Wu, and Bradley R. Barnes (2012), "The Effects of Early Internationalization on Performance Outcomes in Young International Ventures: The Mediating Role of Marketing Capabilities," Journal of International Marketing, 20(4), 25-45.

*Zou, Shaoming, Eric Fang, and Shuming Zhao (2003), "The Effect of Export Marketing Capabilities on Export Performance: An Investigation of Chinese Exporters," Journal of International Marketing, 11(4), 32-55.

\footnotetext{
* denotes the 64 articles included in the systematic review in Tables $1 \mathrm{~A}, 1 \mathrm{~B}$ and $1 \mathrm{C}$.
} 